\title{
Intralesional bleomycin versus sodium tetradecyl sulphate in the management of peripheral lymphangiomas in children: a prospective comparative study
}

\author{
Nayak K. ${ }^{1}$, Tripathy P.K. ${ }^{2}$, Jena P.K. ${ }^{3}$, Mohanty H.K. ${ }^{4}$ \\ ${ }^{1}$ Dr. Nayak K, Senior Resident, ${ }^{2}$ Dr. Tripathy P.K., Assistant Professor, ${ }^{3}$ Dr. Jena P.K., Professor, ${ }^{4}$ Dr. Mohanty \\ H.K., Professor, all authors are affiliated with Department of Pediatric Surgery, S.V.P. Postgraduate Institute of \\ Pediatrics. Cuttack, Odisha, India.
}

Address for Correspondence: Dr. P.K. Tripathy, Department of Pediatric Surgery, S.V.P. Postgraduate Institute of Pediatrics, Cuttack, Odisha, Email: drpktripathy555@gmail.com

\begin{abstract}
Introduction: Surgical resection in lymphangiomas is associated with high rate of complications, recurrences and total excision is not possible in every case. Therefore, sclerotherapy have emerged as alternative mode of management. It is essential to know the efficacy of the sclerosants and the merits and demerits of the agents. However, a prospective study comparing the efficacies of the sclerosing agents exclusively on lymphangioma is lacking. Methods: A prospective, comparative clinical trial was conducted in a tertiary health care pediatric institute among lymphangioma patients. Patients were divided into two groups by randomisation; Group A: patients in whom intralesional bleomycin injection was administered, Group B: patients in whom intralesional sodium tetradecyl sulphatewas administered. Both the groups were compared with respect to clinical presentation, efficacy of the drugs and side effects/complications. Result: Out of 36 patients included in this study, 18 patients were treated with intralesional bleomycin and 18 patients with intralesional sodium tetradecyl sulphate. Most common site of lymphangioma was neck (44.5\%) followed by axilla in $27.7 \%$ of cases. Reduction in size was noted in $15(83.3 \%)$ patients in group A, 9 (50\%) had excellent response, while $6(33 \%)$ had good response. Reduction in size was noted in $12(66 \%)$ patients in group B, $5(27 \%)$ had excellent response while $7(38 \%)$ had good response. Conclusion: Intralesional bleomycin and sodium tetradecyl sulphate are safe and effective sclerosing agents in peripheral lymphangiomas of children, but bleomycin is more effective in reducing the size of the lesions.
\end{abstract}

Key words: Bleomycin, Lymphatic malformations, Sclerosing agents, Sodium tetradecyl sulphate

\section{Introduction}

Lymphangioma is a developmental malformation of lymphatic system. The reported incidence of the lesion is 1.5 to 2.8 per 1000 and there is no specific sex or race predilection [1]. It is usually seen in pediatric age group and constitutes $6 \%$ of benign tumors in this age group [2]. In about $50 \%$ of patients, the disease is found at birth and 80 to $90 \%$ of cases present before 2 years of age [3]. Head and neck area is the commonest site affected by lymphangioma $[1,4]$. Sites other than head and neck include axilla, mediastinum, thigh, chest and

Manuscript received: $30^{\text {th }}$ October 2017

Reviewed: $8^{\text {th }}$ November 2017

Author Corrected: $17^{\text {th }}$ November 2017

Accepted for Publication: $23^{\text {rd }}$ November 2017 abdominal wall [5]. Landing and Ferber classified lymphatic malformationsinto 3 types (i) Lymphangioma simplex: consisting of thin lymphatic channels of capillary size, (ii) Cavernous lymphangioma: composed of dilated lymphatic channels, (iii) Cystic lymphangioma: consists of cysts having diameter of few millimeters to centimeters $[6,7]$. Combinationof these groups are frequently detected in the same lesion.

Management of lymphatic malformations are complicated and challenging. Surgical resection is the traditional modality of management but is associated with high rate of complications and total 
excision is not possible in every case. The reported recurrence rate after resection of lymphangioma varies from 15 to $53 \%[7,8]$. Therefore, nonsurgical methods such as sclerotherapy have emerged as alternative mode of management. Sclerosants act by destroying the epithelial lining of the cysts followed by collapse and scarring [7,9]. Sclerosing agents such as Ethanol and Sodium tetradecyl sulphate (STS) became popular initially and are commonly used $[8,9]$. However, in the recent years OK-432 and Bleomycin are favoured by many surgeons due to encouraging results. But, OK-432 is not easily available and is costly [6,7]. Bleomycin was first discovered as a cytotoxic antitumor antibiotic and later on used as a sclerosing agent in lymphangiomas [10,11]. It has specific effect on vascular endothelium and inflammation is the mechanism of action. We were using bleomycin and STS, as both are readily available in our locality and are economical. It is essential to know efficacy of the sclerosants and the merits and demerits of both the agents. However, a prospective studycomparing the efficacies of the two sclerosing agents exclusively on lymphangioma is not available.

On this background the present study was conducted in our tertiary health care Pediatric Surgical Institute as a prospective, controlled and comparative clinical trial. The aim of the study was to evaluate, assess and to compare the efficacy of two common sclerosants; bleomycin and STS in the management of lymphangiomas in children.

\section{Methods}

The study was carried out in the department of pediatric surgery at SVP Postgraduate Institute of Pediatrics, SCB Medical College, Cuttack, Odisha, India from November 2014 to October 2016 and follow up till October 2017. This was a prospective, comparative, controlled clinical trial. Lymphangioma patients attending the OPD of this tertiary health care hospital were examined and assessed. Children only with peripheral lymphangiomaswere included in the study. Patients having intra-abdominal or visceral lymphangioma andpostoperative recurrent lymphangiomaswere excluded. The detailed history and physical examination of all patients were recorded.The diagnosis was based on clinical examination and ultrasound scan [Figure-1].
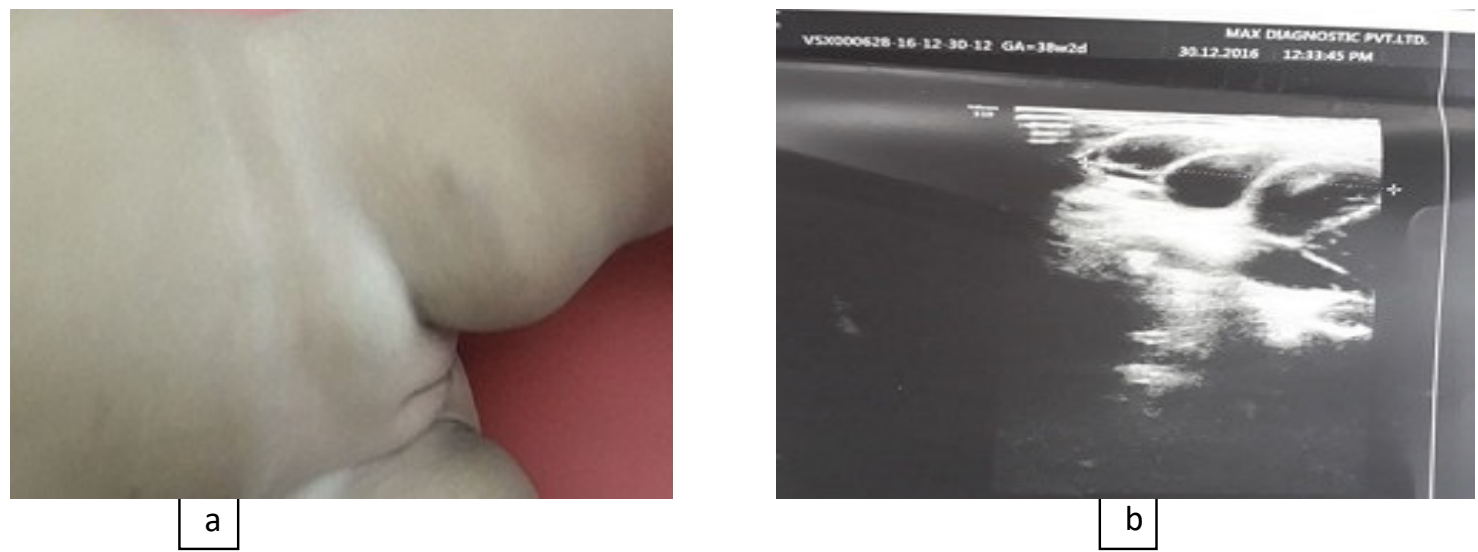

Figure-1: (a) A 2-year-old female child with swelling on anteromedial aspect of left thigh, (b) Ultrasongraphy showing soft tissue lesion with cystic spaces; no vascularity could be appreciated on colour Doppler within the lesion, underlying muscles of thigh normal. She was successfully treated by intralesional sclerotherapy with two injections of STS at 4-week interval.

Routine hemogram and X-ray were performed. Patients were divided into two groupsby randomization; Group A: patients in whom intralesional bleomycin injection was administered, Group B: patients in whom intralesional STS was administered. Each group had equal number of patients according to age and the siteof lymphangioma so as to assess the efficacy of drugs accurately. Written informed consent was taken from the parents after counseling regarding the mode of treatment, merits and demerits of the procedure.

Normal saline $(15 \mathrm{ml})$ was added to $15 \mathrm{mg}$ bleomycin powder in the vialto prepare a strengthof $1 \mathrm{mg} / \mathrm{ml}$. The dose of bleomycin was calculated as $0.5 \mathrm{mg} / \mathrm{kg}$ body weight and was taken from the reconstituted solution. It was again 
diluted in $10 \mathrm{ml}$ normal saline. Cyst content was aspirated with a 10cc disposable syringe with 20-24 gouge needle. The needle was placed in situ and bleomycin solution was injected slowly. Patients were kept on observation for at least 24 hours. Fever, pain and swelling at the injection site were specially looked for and managed accordingly. On discharge, parents were advised for follow up at 4 weeks. The size of the lesion was recorded and injection was repeated at four-weeks intervals with same dosage, with a maximum of four injections. Each patient had clinical assessment and ultrasound scan on each visit, to assess the size reduction of the lesion. Similarly, intralesional STS was given at the dose of 1 to $3 \mathrm{ml}$ of $2 \%$ solution depending on the size of the lesion at an interval of 4 weeks. The patients were followed for 1 year to 2 years (mean follow up 11/2 year). The response was measured clinically (size of lesion) and radiologically (ultrasonography) andgraded as follows;

1. Excellent (regression of lesion size $>90 \%$ ),

2. Good (regression of size $50-90 \%$ ) and

3. Poor (less than $10 \%$ or no response).

The data was recorded for the frequency and percentage of patientsand analysis was done. Both the groups were compared with respect to clinical presentation, efficacy of the drugs and side effects/complications.

\section{Results}

Out of 36 patients included in this study, 18 patients were treated with intralesional bleomycin (group A) and 18 patients (group B) with intralesional STS. The age range wasfrom 18 days to 7 yearswith 17 patients below one year of age. Fifteen patients were between 1 to 2 year of age and 4 children above 2 years of age.Both the groups contained $11(61.1 \%)$ malechildren and 7 (38.9\%) female children; the male to female ratio being 1.57:1. Most common site of lymphangioma was neck in $44.5 \%$ cases [Figure-2] followed by axilla in $27.7 \%$ of cases [Table$1]$.

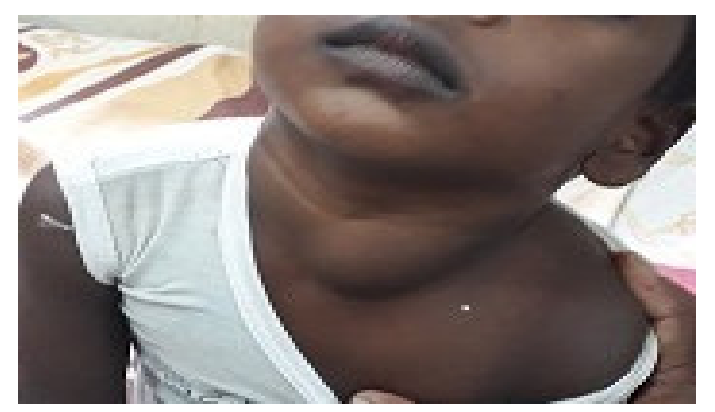

Figure-2: A 3-year-old male child with lymphangioma of left cervical region. He was found to have cystic variety of lymphangioma and treated with two injections of intralesional bleomycin $(0.5 \mathrm{mg} / \mathrm{kg}$ body weight $)$ at 4 week interval.

Table-1: Site of the lesions treated with sclerotherapy.

\begin{tabular}{|c|c|c|}
\hline Site of lesion & Intralesional bleomycin & Intralesional STS \\
\hline Neck & 8 & 8 \\
\hline Axilla & 5 & 2 \\
\hline Parotid & 2 & 1 \\
\hline Back & 1 & 2 \\
\hline Limbs & 2 & 5 \\
\hline
\end{tabular}

Cervical area is the most common site of lymphangioma (44.5\%) followed by axillary area (27.7\%).

We found simplex type of lymphangioma in 12 patients, cystic lymphangioma in 18 patients and the rest 6 patients were having cavernous type of lymphangioma. 50\% of the lesions in each category were administered with intralesional bleomycin and the rest $50 \%$ were administered with intralesional STS. 


\section{Response to intralesional sclerotherapy}

Intralesional bleomycin sclerotherapy: Reduction in size was noted in 15 (83.3\%) patients in group A, 9(50\%) had excellent response, while 6(33.3\%) had good response [Table-2].

Table-2:Clinical response to intralesional sclerotherapy

\begin{tabular}{|c|c|c|}
\hline & $\begin{array}{c}\text { (Gr A) Intralesional } \\
\text { bleomycin(n=18) }\end{array}$ & $\begin{array}{c}\text { (Gr B) IntralesionalSTS (n } \\
\text { =18) }\end{array}$ \\
\hline Reduction in size & $15(83.3 \%)$ & $12(66.7 \%)$ \\
\hline Excellent response & $9(50 \%)$ & $5(27.8 \%)$ \\
\hline Good response & $6(33.3 \%)$ & $7(38.9 \%)$ \\
\hline Poor response & $3(16.7 \%)$ & $6(33.3 \%)$ \\
\hline
\end{tabular}

Intralesional bleomycin is more effective in reducing the size of the lesions than intralesional STS.

Three patients (16.7\%) had poor response. Out of nine patients with excellent response on bleomycin therapy, 6 cases were lymphangioma simplex type, and they had regression of lesion with one injection of bleomycin. Rest3 cases were cystic type and required two injections of bleomycin. All the 6 patients having good response were cystic variety and they needed 4 injections of bleomycin at 4 weekintervals. Three patients with poor response were cavernous types. Fever was found in 3 patients, which was subsided within two days with oral paracetamol. Cellulitis as observed by pain, redness and swelling of the lesion was assessed in three more patients. These children were treated with antibiotics and analgesics. There was no serious side effect or systemic toxicity.

Intralesional STS sclerotherapy:Reduction in size was noted in $12(66.7 \%)$ patients in group B, $5(27.8 \%)$ had excellent response while $7(38.9 \%)$ had good response [Table-2]. All 5 patients with excellent response were lymphangioma simplex. Two had regression of lesion with one injection of STS and three with two injections. Among the 7 patients having good response to STS, one was simplex type and 6 were cystic variety lymphangiomas.All had 4 number of injection at 4 weekintervals. Six patients $(33.3 \%)$ had poor response and three of them were multiloculated cystic type and rest three were cavernous types.Cellulitis and transient increase in size was assessed in three and two patients respectively and were treated conservatively with antibiotics and analgesics. Systemic side effect or toxicity was not detected.

All the patients in both the groups were followed for 1-2 years. Recurrence or increase in size was not found in excellent and good response category of children. There was no scarring or pigmentation at the site of injection in either group of patients. No other complication related to intralesional sclerotherapy was found in any of these patients. Serious side effects or pulmonary fibrosis was not detected. Patients with poor response were advised for surgical intervention in our routine operation theater. Out of total 9 children 7 patients were operated during follow up period with complete removal of the lesion in all cases. Postoperatively all the parents were satisfied regarding our treatment plan and outcome.

\section{Discussion}

Vascular lesions are traditionally classified into two broad categories: Hemangiomas and Vascular malformations (VM). VM are further divided depending on the type of vessel involved; capillary, arterial, venous, lymphatic malformation or mixed lesions [12]. Capillary, venous and lymphatic malformations are classically categorized as 'low flow' lesions as compared to arterial or arteriovenous malformations which are 'high flow' lesions [13]. Lymphatic malformations may be subdivided into microcystic (diameter $<1 \mathrm{~cm}$ ), macrocystic or mixed lesions [9].The pathogenesis of the anomalies is unknown, but there is an error in the morphogenesis of lymphatic vessels [14]. There is a failure of communication of lymphatic channels to venous system [8].

By rule, vascular malformations are present at birth, but may not be clinically evident in all cases. Being classified under VM, lymphatic malformations are detected at birth in about $60 \%$ of the patients and most of the lesions are 
recognized before 2 years of age [3]. Lymphangiomas grow in proportionate with the growth of the child [15]. They enlarge by hypertrophy in contrast to hemangiomas which grow by hyperplasia [16]. They usually displace adjacent organs, but there may be abrupt expansion of the lesion due to infection and haemorrhage [16]. Lymphatic malformations are unique among VM in that they may enlarge during systemic illness like viral or bacterial infection [8]. Lymphangiomas usually affect both sexes equally $[2,16]$. In our study male to female ratio was 1.57:1. This may be due to the fact that more of the male children are referred to us from periphery or more importance being given to male babies in some areas. Head and neck is the most commonly involved site $[4,16]$. The commonest site of lymphangioma seen in our study was neck (44.5\%) followed by axilla (27.7\%). Anatomically, neck and axillary areas are associated with major lymphatic channels, so there is increased preference for lymphatic malformations [8]. We followed the classification system described by Landing and Ferber. In our study, $50 \%$ of the lesions were cystic type of lymphangioma, 33.3\% simplex type and the rest $16.7 \%$ were of cavernous variety. Like other vascular malformations, lymphangimasdo not show signs of involution. This is in contrast tohemangiomas which show proliferative phase followed by slow and spontaneous involution [16]. Lymphatic malformations can cause significant morbidity due to cosmesis, compression of adjacent structures, inflammation and internal haemorrhage [6,7].

Management of lymphatic malformations is still challenging for the surgeons. Although, surgical excision can provide an effective cure for these anomalies, the outcome depends on the anatomical location, extent, involvement of adjacent tissue and expertise of the surgeon. Total resection is not possible in every case because of extensive lesion, infiltrating nature of the tumorand involvement of vital structures in some cases $[2,5]$. Postoperative complications like feeding difficulties, infection and airway obstruction especially in lymphangiomas of cervical areas (most common location) are of significant concern. Wound infection, nerve palsy and residual scars are also possible complications [17]. High recurrence rate reported by many surgeons, complicates the treatment plan [6,7]. The fact that 'lymphangiomas are benign tumors' should be kept in mind before considering other treatment options. Management of lymphangiomasare cosmetically important as they are commonly seen in vital areas such as head and neck. Therefore, nonsurgical methods have emerged as alternative modes of management. These include radiotherapy, argon beam ablation therapy, lasers; $\mathrm{CO} 2$ and more effectively Nd-YAG laser and sclerotherapy[7,16]. But, sclerotherapy gained more popularity and continued to be choice of nonsurgical management in Lymphatic malformations.

Sclerotherapy is preferred in many centres because of risks associated in surgical intervention, anaesthesia, postoperative complications and recurrence rate. However, the choice of an ideal sclerosing agent and the exact dosage of the intralesional drug are still controversial. Ideal sclerosing agent should produce adequate destruction of the lesion and lack systemic toxicity [18]. The agent should be safe, inexpensive and easily available. Sclerosing agents such as Ethanol, OK-432, Bleomycin and STS are tried with variable outcome. Ethanol sclerotherapy is associated with problems like skin necrosis, nerve injury and systemic effect $[2,19]$. Ethanol may enter vascular system causing hypotension and lethal intoxication [20]. OK-432 is a lyophilized incubation mixture of Group A Streptococcus Pyogenes [2]. It causes cytokine mediated endothelial permeability leading to shrinkage of cystic spaces and regression of LM. OK-432 may cause transient local inflammation in some cases and there is a risk of airway compression in cervical lesions [21]. Rozman et al. reported a patient, who received 3 dosages of OK-432 injection after failure with bleomycin sclerotherapy [1]. The lesion also failed to respond to OK-432 and surgical intervention was undertaken. OK-432 is not yet approved by U.S. Food and Drug Administration [2]. The cost and availability of the drug are prohibiting factors [7,17,22].

Bleomycin was first introduced into medical literature in 1966 by Umezawa et al. as aglycopeptide antibiotic[10]. Surprisingly it was never used as an antibiotic. It was found to have cytotoxic antitumor properties and presently established as an anticancer drug. Its effect towards sclerosing agent was first described by Yura et al. in 1977[11]. It causes DNA intercalation, strand breaks and free radical formation [1]. The drug acts on the endothelial lining of lymphatic vessels $[1,2,23]$. Although the exact mechanism of action in lymphangioma is unknown, it is inflammatory mediated as there occurs transient increase in the size of lymphangioma after intralesional injection [24]. Bleomycin took about two decades and several trials to be popularized as an efficient sclerosant $[5,23,25]$. The minimum dose of intralesional bleomycin is described as $1 \mathrm{mg} / \mathrm{kg}$ body weight and the 
summated dose as $5 \mathrm{mg} / \mathrm{kg}$ body weight [3,5,22]. But, the effective dose of bleomycin for sclerosis will depend upon, the availability of drug per unit surface area. Drug availability will be increased after aspiration of fluid in the lesion. Complete aspiration should be the goal to avoid dilution of the drug. Therefore, we gave more emphasis on complete aspiration of cyst and administration of minimum amount of drug to avoid local and systemic complications. The dosage of our study and schedule of administration was similar to other studies but, we have administered lowest summated dose among these studies $[5,22,26]$.

Side effects after bleomycin therapy includes allergy, flu-like symptoms, skin pigmentation, hair loss and mucositis [2,9]. Pulmonary toxicity is a notable side effect with bleomycin, but it is dose related [6,7]. The sequel of toxicity includes diffuse alveolar damage, interstitial pneumonitis followed by progressive pulmonary fibrosis [27]. The risk for pulmonary toxicity is reported when the single dose of Bleomycin is more than $30 \mathrm{mg} / \mathrm{m}^{2}$ of body surface area or the total dose exceeds 400U [7,17,22]. Pulmonary fibrosis due to intralesional bleomycin is not yet reportedeven in clinical studies from Australia, Japan, Malaysia and Pakistan $[1,17,28]$. We have also not reported pulmonary toxicity in follow up of our patients due to a safe and low dose of administered bleomycin. A low concentration of enzyme bleomycin hydrolase may account for the susceptibility of these tissues for bleomycin toxicity [29]. The enzyme may also be deficient in patients having pulmonary and skin toxicities due to bleomycin [27]. STS is a sclerosing agent for VM, which causes obliteration of vessels followed by adventitial fibrosis and luminal collapse [14]. STS is used for sclerotherapy in lymphangiomas in some centres and authors published their encouraging results $[30,31,32]$. It is found to be effective and safe sclerosant.

The sclerosing effect of bleomycin solution will be higher after complete aspiration of the lesion due to increased availability of the drug per unit area. Poor response with intralesional bleomycin may occur due to partial aspiration of lesion before injecting sclerosant or mixed variety of Lymphatic malformation. Although, the dose of bleomycin used in different studies is variable, we have used $0.5 \mathrm{mg} / \mathrm{kg} / \mathrm{dose}$, which is much lower than the development of potential complication especially pulmonary toxicity. In our study reduction in size was noted in $83.3 \%$ cases with excellent results i.e. complete regression in $50 \%$ cases. The results are comparable with other studies [Table-3].

Table-3: Comparison of the results in different series.

\begin{tabular}{|c|c|c|c|c|}
\hline Study & Year & $\begin{array}{c}\text { Total no of } \\
\text { patients }\end{array}$ & $\begin{array}{c}\text { Significant regression (size } \\
\text { resolution }>\mathbf{5 0 - 1 0 0 \% )}\end{array}$ & $\begin{array}{c}\text { Excellent response (size } \\
\text { regression>90\%) }\end{array}$ \\
\hline Tanaka et al [5] & 1990 & 47 & $41(87 \%)$ & $20(43 \%)$ \\
\hline Oxford et al [24] & 1995 & 16 & $14(87.5 \%)$ & $7(43.75 \%)$ \\
\hline Mahajan et al [23] & 2004 & 15 & $13(86.7 \%)$ & $8(53.3 \%)$ \\
\hline Saddal et al [18] & 2007 & 33 & $29(90 \%)$ & $10(30 \%)$ \\
\hline Rozman et a [11] & 2011 & 24 & $20(83 \%)$ & $15(62.5 \%)$ \\
\hline Present Study & 2017 & 18 & $15(83.3 \%)$ & $9(50 \%)$ \\
\hline
\end{tabular}

Comparison of the results in series using bleomycin,Intralesional bleomycin is effective in reducing the size of lymphangiomas in $83-90 \%$ cases with excellent response varying from $30-62.5 \%$ cases in different series.

Excellent and good response was noted in simplex and cystic varieties and poor response in cavernous types. Okada et al. and Rawat et al. reported similar findings; good response to bleomycin in cystic varieties than cavernous types $[3,7]$. Authors reported better effect of bleomycin in cystic variety as compared to cavernous and capillary types $[5,22,23]$. However, our study revealed that bleomycin is also effective in capillary varieties of lymphatic malformations.

OK-432 is effective in macrocystic lymphangioma and its effectiveness is limited in microcystic lesions [2]. So authors suggested its use in simple lymphatic cysts and macrocystic lesions. They also recommended surgical intervention after OK-432 sclerotherapy in microcystic and cavernous type of lesions [33]. However, we have noted significant response in $83.3 \%$ of our cases with bleomycin sclerotherapy alone. Studies on intralesional 
aqueous solution of bleomycin in lymphangioma is limited [3,7,23]. A single study exclusively on lymphangiomasfor comparison between two sclerosantswith respect to their effectiveness, side effects and complications is not reported [1]. This is a prospective controlled clinical trial exclusively on lymphatic malformationscomparing two established agents to find out the most effective sclerosant and the management approach in a tertiary health care paediatric institute.

Contribution of this study towards existing knowledge- Although, both bleomycin and STS are used as sclerosing agent in lymphangioma, this clinical trial revealed, bleomycin to be more effective in reducing the size of the lesions in children. When administered properly and in proper dose $(0.5 \mathrm{mg} / \mathrm{kg}$ body weight), bleomycin is very safe without serious side effect, especially pulmonary fibrosis described in literature. Although, authors reported better effectiveness of bleomycin in cystic variety as compared to other types, we found bleomycin is also very effective in capillary variety of lymphatic malformations.

\section{Conclusion}

Lymphangiomas in children are detected most commonly in cervical area followed by axilla, which are cosmetically important. Intralesional bleomycin and STS are effective alternatives to surgery in lymphangiomas.

Both the sclerosants are safe in children, without any serious side effects or pulmonary complications, when administered properly and in proper doses.

However, bleomycin is more effective in reducing the size of the lesions than STS.

Excellent and good response to the drugs should be expected in simplex and cystic variety of the lymphangiomas as compared to cavernous variety of the lesion.

We together with other published studies support the use of intralesional sclerotherapy as first-line of treatment for peripheral lymphangiomas in children. Surgery should be reserved for the lesions, failed to respond to sclerotherapy.

Contribution by authors: Nayak K: Data collection and processing, Tripathy PK (corresponding author): Data management and reporting, literature review, logical interpretation and presentation of the results construction of the whole of the manuscript, Jena PK: Reviewing the article before submission, Mohanty HK: Hypothesis for research, planning methodology

Abbreviations: STS- Sodium tetradecyl sulphate, VM- Vascular malformations.

Conflict of interest: None initiated, Perission from IRB: Yes

\section{References}

1. Rozman Z, Thambidorai RR, Zaleha AM, Zakaria Z, Zulfiqar MA. Lymphangioma: Is intralesional bleomycin sclerotherapy effective? Biomed Imaging Interv J. 2011 July-Sep; 7(3): e 18. doi:10.2349/biij. 7.3.e18.

2. Wiegand S, Eivazi B, Zimmermann AP, Sesterhenn AM, Werner JA. Sclerotherapy of lymphangiomas of the head and neck. Head Neck. 2011 Nov;33(11):1649-55. doi: 10.1002/hed.21552. Epub 2010 Aug 24.

3. Okada A, Kubota A, Fukuzawa M, Imura K, Kamata S. Injection of bleomycin as a primary therapy of cystic lymphangioma. J Pediatr Surg. 1992 Apr;27(4):440-3.

4. Kennedy TL, Whitaker M, Pellitteri P, Wood WE. Cystic hygroma/ lymphangioma: a rational approach to management. Laryngoscope. 2001 Nov; 111 (11Pt1): 1929-37.

5. Tanaka K, Inomata $\mathrm{Y}$, Utsunomiya $\mathrm{H}$, Uemoto $\mathrm{S}$, Asonuma K, Katayama T,etal. Sclerosing therapy with bleomycin emulsion for lymphangioma in children. Pediatr Surg Int. 1990; 5: 270-3.

6. Niramis R, Watanatittan $\mathrm{S}$, Rattanasuwan $\mathrm{T}$. Treatment of cystic hygroma by intralesional bleomycin injection: experience in 70 patients. Eur $\mathrm{J}$ Pediatr Surg. 2010 May;20(3):178-82. doi: 10. 1055/s-0030-1247548. Epub 2010 Feb 22.

7. Rawat JD, Sinha SK, Kanojia RP, Wakhlu A, Kureel SN, Tandon RK. Non surgical management of cystic lymphangioma. Indian J Otolaryngol Head Neck Surg. 2006 Oct; 58 (4): 355-7. doi: 10. 1007/ BF030 49593. 
8. Kulungowski AM, Fishman SJ. Vascular anomalies. In: Coran AG, Adzick NS, Krummel TM, Laberge J, Shamberger RC, Caldmone AA. Editors. Pediatric Surgery. $7^{\text {th }}$ ed. Elsevier Saunders 2012. Pp. 1613-30.

9. Rialon KL, Fishman SJ. Vascular and lymphatic anomalies. In: Holcomb III GW, Murphy JP, Ostie DJ. Editors. Ashcraft's Pediatric surgery. $6^{\text {th }}$ ed. Elsevier Saunders 2014. Pp. 1007-27.

10. Umezawa H, Maeda K, Takeuchi T, Okami Y. New antibiotics, bleomycin A and B. J Antibiot (Tokyo). 1966 Sep;19(5):200-9.

11. Yura J, Hashimoto T, Tsuruga N, Shibata K. Bleomycin treatment for cystic hygroma in children. Nihon Geka Hokan. 1977 Sep 1;46(5):607-14.

12. Mulliken JB, Glowacki J.Hemangiomas and vascular malformations in infants and children: a classification based on endothelial characteristics. Plast Reconstr Surg. 1982 Mar; 69 (3): 41222.

13. Mulliken JB. Cutaneous vascular anomalies. Semin Vasc Surg. 1993 Dec;6(4):204-18.

14. Svendsen PA, Wikholm G, Rodriguez M, Enoksson P, Frisén L, Stromland K, Seregard S. Direct puncture and sclerotherapy with Sotradecol: Orbital lymphatic malformations. IntervNeuroradiol. 2001 Sept; 7(3): 193-9. doi: 10.1177/159101990 100700303 .

15. Barsky SH, Rosen S, Geer DE, Noe JM. The nature and evolution of port wine stains: a computer-assisted study. J Invest Dermatol. 1980 Mar; 74 (3):154-7.

16. Werner JA, Dünne AA, Folz BJ, Rochels R, Bien S, Ramaswamy A, Lippert BM. Current concepts in the classification, diagnosis and treatment of hemangiomas and vascular malformations of the head and neck. Eur Arch Otorhinolaryngol 2001Mar; 258(3): 141-9.

17. Saddal NS, Sharif A, Ahmad S, Mirza F, Akhtar N, Haq A, Jan Ahmed I. Intralesional bleomycin injection: A primary therapy for peripheral lymphangiomas. Pak J Med Sci 2007; 23(2): 220-2.
18. Perper M, Cervantes J, Eber AE, Hsu VM, Alharbi M, Omair IA, Alfuralh A Nouri K. Lymphangioma Circumscriptum: Treatment Modalities for this un yielding condition. J Clin Investigat Dermatol. 2017; 5(1): 2.

19. Alomari AI, Karian VE, Lord DJ, Padua HM, Burrows PE. Percutaneoussclero therapy for lymphatic malformations: a retrospective analysis of patient-evaluated improvement. J Vasc Interv Radiol. 2006 Oct;17(10): 1639-48.

20. Gelczer RK, Charboneau JW, Hussain S, Brown DL.Complications of percutaneous ethanol ablation. J Ultrasound Med. 1998 Aug;17(8):531-3.

21. Giguere CM, Bauman NM, Sato Y, Burke DK, Greinwald JH, Pransky S, Kelley P, Georgeson K, Smith RJ. Treatment of lymphangiomas with OK432(Picibanil) sclerotherapy: a prospective multiinstitutional trial. Arch Otolaryngol Head Neck Surg. 2002 Oct; 128(10): 1137-44.

22. Mahajan JK, Bharathi V, Chowdhary SK, Samujh R, Menon P, Rao KLN. Bleomycin as intralesional sclerosant for cystic hygromas. J Indian Assoc Pediatr Surg. 2004; 9: 3-7.

23. Orford J, Barker A, Thonell S, King P, Murphy J. Bleomycin therapy for cystic hygroma. J Pediatr Surg. 1995 Sep;30(9):1282-7.

24. Baskin D, Tander B, Bankaoğlu $M$. Localbleomycin injection in the treatment of lymphangioma. Eur J Pediatr Surg. 2005 Dec; 15 (6): 383-6.

25. Zhong PQ, Zhi FX, Li R, Xue JL, Shu GY.Long-termresults of intratumorousbleomycinA5injection for head and necklymphangioma. Oral Surg Oral Med Oral Pathol Oral Radiol Endod. 1998 Aug; 86(2):139-44.

26. Nirmis R, Watanatittan $\mathrm{S}$, Rattanasuwan $\mathrm{T}$. Treatment of cystic hygroma by intralesional bleomycin injection: experience in 70 patients. Eur J Pediatr Surg 2010 May; 20(3): 178-82. doi: $10.1055 /$ s- 0030-1247548.

27. Hapani S, Chu D, Wu S. Eosinophilic pneumonia associated with bleomycin in a patient with mediastinal seminoma: a case report. Journal of 
Medical Case Reports. 2010 Dec; 4: 126. doi.org /10. 1186/1752-1947-4-126.

28. Ikram Ud Din, Inayat-ur-Rehman, Rasool G, Khan AR, Shah e Din. Intralesional bleomycin therapy of cystic hygroma in children. J Med Sci 2008; 16(2): 87-90.

29. Dorr RT.Bleomycinpharmacology: mechanism of action and resistance, and clinical pharmacokinetics. Semin Oncol. 1992 Apr; 19 (2S uppl 5): 3-8.

30. Harjai MM, Jha M. Intralesional bleomycin and sodium tetradecyl sulphate for haemangiomas and lymphangiomas. Afr J Paediatr Surg. 2012 Jan-Apr; 9 (1):47-51. doi: 10.4103/0189-6725.93304.
31. AlGhamdi KM, Mubki TF. Treatment of lymphangioma circumscriptum with sclerotherapy: an ignored effectiveremedy. J Cosmet Dermatol. 2011 Jun; 10 (2):156-8. doi: 10.1111/j.1473-2165. 2011. 00558.x.

32. Poonyathalang A, Preechawat P, Jiarakongmun P, Pongpech S. Sclerosing therapy for orbitally mphangioma using sodium tetradecyl sulfate. JpnJ Ophthalmol. 2008 Jul-Aug;52(4): 298-304. doi: 10.1007/s10384-008-0547-5. Epub 2008 Sep 5.

33. Okazaki T, Iwatani S, Yanai T, Kobayashi H, Kato Y, Marusasa T, Lane GJ, Yamataka A. Treatment of lymphangioma in children: our experience of 128 cases. J Pediatr Surg. 2007 Feb;42 (2): $386-9$.

\section{How to cite this article?}

Nayak K, Tripathy P.K, Jena P.K, Mohanty H.K. Intralesional bleomycin versus sodium tetradecyl sulphate in the management of peripheral lymphangiomas in children: a prospective comparative study. Int J Pediatr Res. 2017;4(11):657-665. doi:10.17511/ijpr.2017.i11.05. 